\title{
Application of Capture and Recapture Method for Estimating the Population Size of Men Who Have Sex with Men in Chiang Mai, Thailand
}

\author{
Phrutthinun Surit ${ }^{1,2}$, Ning Zheng ${ }^{3}$, He Yi ${ }^{3}$, Xiaojing $\mathbf{Y u}^{3}$, Watcharee Srithong ${ }^{4}$, Saisiri Mirasena1,2, \\ Wutthichai Jariya ${ }^{*}$
}

${ }^{1}$ Faculty of Medical Science, Naresuan University, Phitsanulok, Thailand

${ }^{2}$ Center of Excellence in Medical Biotechnology (CEMB), Phitsanulok, Thailand

${ }^{3}$ Shanghai Municipal Center for Disease Control \& Prevention, Shanghai, China

${ }^{4}$ Faculty of Public Health, Naresuan University, Phitsanulok, Thailand

Email: *wutthichai2002@hotmail.com

How to cite this paper: Surit, P., Zheng, N., Yi, H., Yu, X.J., Srithong, W., Mirasena, S. and Jariya, W. (2016) Application of Capture and Recapture Method for Estimating the Population Size of Men Who Have Sex with Men in Chiang Mai, Thailand. World Journal of AIDS, 6, 197-204.

http://dx.doi.org/10.4236/wja.2016.64022

Received: August 25, 2016

Accepted: December 12, 2016

Published: December 15, 2016

Copyright $\odot 2016$ by authors and Scientific Research Publishing Inc.

This work is licensed under the Creative Commons Attribution International

License (CC BY 4.0).

http://creativecommons.org/licenses/by/4.0/

(c) (i) Open Access

\begin{abstract}
Background: Men who have sex with men (MSM) are highly vulnerable to HIV infection, but this population can be particularly difficult to reach in Thailand. This study aimed to estimate the number of MSM in Chiang Mai Thailand, in order to plan HIV control and prevention. Methods: The total of 348 potential MSM were identified at eight contact locations, including two public parks, two bars, two massage parlors and two pubs in Chiang Mai. Trained 16 research enumerators and 16 enumerators were trained to extend a recruitment of brooches to MSM. The MSMs were captured one week apart. A record was kept of when, where and by whom the invitation was extended and received, and of refusals. The total estimate of MSM was derived from capture-recapture calculation. Results: The total MSM in Chiang Mai Thailand estimated by capture and recapture method was $733(95 \% \mathrm{CI}=480-948)$ or the estimate was $7.3 \%(95 \% \mathrm{CI}=7.1 \%-14.1 \%)$. Conclusions: Capture and recapture method can be used to enumerate and provide accurate and reliable estimates of the MSM population in any area, provided that certain conditions are controlled. MSM who are engaged in personal community represent a sizeable population who urgently need to be targeted by HIV and STDs prevention strategies.
\end{abstract}

\section{Keywords}

MSM, HIV, Capture and Recapture, Thailand

\section{Introduction}

Men who have sex with men (MSM) are an inclusive public health term used to define 
sexual behavior of men having sex with other men [1]. It is the preferred term in the context of HIV because the important issue is risk behavior rather than sexual identity. It does not refer to an identifiable community or gender identification. MSM includes not only self-identified gay/homosexual and bisexual men, but also men who engage in sex with men and women and self-identify as heterosexual. For example, certain situations, such as in prisons or military service, may result in men engaging in sexual intercourse with other men when they would not do so in other contexts [1].

Estimation of HIV/AIDS prevalence is very important, because it reflects the primary state of HIV/AIDS epidemic in a country. The estimates are cornerstones of evidencebased policy making, which directs medical resource allocation, service planning and targeting of good interventions, and, potentially, monitoring possible impact [1] [2]. The pattern of the estimation is specified by the levels of the epidemic. To estimate HIV/AIDS prevalence in low-level and concentrated epidemics, as that in Thailand, it is necessary to disaggregate the total adult population into sub-populations based on the relative risk of infection [3]. The identity of these hard-to-reach populations varies from country to country, which, nevertheless, usually include injecting drug users (IDU), men who have sex with men (MSM), sex workers, and migrant populations [2] [4]. Of all the populations above, the MSM population appears to be the most neglected. Countries differ considerably in the visibility and acceptability of MSM. MSM continue to increase the high risk of HIV and other Sexual Transmitted Diseases (STDs) [2]. The statistics from UNAIDS show that at least $5 \%-10 \%$ of HIV cases worldwide are due to sexual transmission between men [4]. The report of HIV prevalence among MSM ranges from $0 \%$ to $32.9 \%$ worldwide [5] [6]. In Bangkok, Thailand, HIV prevalence in cross-sectional surveys of MSM increased rapidly from 17\% in 2003 to $31 \%$ in 2010 [7]. MSM are at increased risk for HIV infection or most at risk populations, also called hidden or hard-to-reach [1] [4] [8]. Some of them are discriminated against and stigmatized. As a result, the MSM group has difficulty for HIV surveillance activities, HIV prevention programmes and care. For current challenges for HIV prevention and to help decision-making, government, programme managers or health providers must know the size of this group [1].

In Thailand, this population is faced with stigma and discrimination, and to estimate its size can be very difficult [9] [10]. Even in countries where people's attitudes towards this group are more open [10], estimates are often based on political or ideological issues rather than on a well-conducted survey [7] [11]. And there are, in reality, few estimate surveys on the MSM population size [4] [7]. While the prevalence of homosexual activity is likely to be far higher than the prevalence of injecting drug use, the necessity of such estimates is not overstressed in a complete assessment on the overall HIV/AIDS prevalence. Methods have been employed to estimate the MSM population size [4] before, but each has its limitations and the task remains difficult and challenging. Our epidemiological survey on the MSM population size in Chiang Mai Province, Thailand, was designed to explore good methods of estimation. Chiang Mai Province is the second largest city in Thailand located in the northern region of Thailand and full 
of tourist throughout the year. There are pubs discotheques massage parlors and host bar for MSM. It is also considered as the HIV/AIDS epidemic area. Therefore, size of MSM population in this area is important for control and prevention of HIV/AIDS.

\section{Method}

Capture-recapture (CR) methods originated among naturalists trying to estimate the size of animal populations. A number of animals are captured, tagged and released [12]. An independent recapture is conducted at a later time in the same area, and the proportion of the captured animals that have already been tagged is calculated. Information on the size of both captures and the proportion captured twice is entered into a mathematical formula to calculate the total size of the population, including the "unseen" portion [3].

$\mathrm{CR}$ is a method of estimating the prevalence of a trait in a population or, more simply, it is a method that provides a pretty good guess of the number of a particular population. The method was initially used to research populations of wild animals, which were captured, marked, released and recaptured. The same statistical process is now used to estimate other types of populations. In this case, this method will be used to estimate the number of MSM in a particular geographic area [12] [13]. The basic idea of capture-recapture studies is to sample and identify individuals, from a population and then resample the population to see what fractions of individuals in the second samples were identified in the first sample (i.e. the fraction of individuals, or cases, that were found in both samples). This method has been found useful in estimating the sizes of hard-to-reach and stigmatized human populations [12] [13] [14]. CR begins with a capture stage, when at one time as many animals as possible in an area are captured, tagged and released. After an interval, the above actions are repeated as a recapture stage. The number of animals in each sample, as well as that common to both, is used to estimate the total number of the population (assuming that the two captures are independent) [14] (Figure 1).

The formula of the capture-recapture method [14]:

$$
\begin{aligned}
& \frac{R}{C}=\frac{M}{N} \\
& N=\frac{C \times M}{R}
\end{aligned}
$$

$R$, is the number common to both captures, $C$, the number of the second capture, $M$, the number of the first capture, $N$, the total population number. The $95 \%$ confidence intervals are determined by calculating the limits for $R / C$, the following formula was used [14] [15]:

$$
95 \% C I=N+1.96 \sqrt{\operatorname{Var}(N)}
$$

where the $\operatorname{Var}(\mathrm{N})$ :

$$
\operatorname{Var}(N)=\frac{C 1 \times C 2 \times(C 1-M) \times(C 2-M)}{M^{3}}
$$




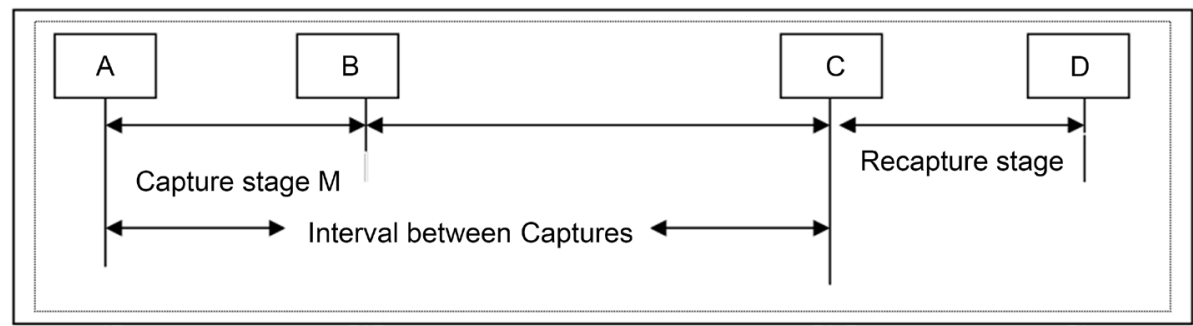

Figure 1. Illustration of the CR.

\section{Field survey}

\subsection{Locations of Survey}

The places where MSM gather in Chiang Mai Province were explored. Eight of them were selected for survey by convenience sampling according to the following principles: the places should have a large capacity and plenty of customers; and the selected places should include as many types as possible. The eight places thereby selected included two bars, two massage parlors, two parks and two pubs.

\subsection{Recruitment of Peer-Staff and Training}

MSM are generally unrecognized in Thailand due to their involvement in stigmatized and socially-unacceptable sexual relationships with other males [10]. Therefore, recruitment of peer-staff was essential for conducting fieldwork. In total, 16 research assistants who are the local populations were recruited for conducting the survey. We were not rigid about the qualifications of peer-staff; rather, the ability to read, write and count was considered sufficient to conduct capture-recapture surveys. The peer-staff handled the field situation confidently and sincerely and gained the cooperation of the target population. Hence, all of the peer-staff were trained about/in field trips, capture and recapture method, field notes and trial practice.

\subsection{Field Implementation of CR Surveys}

After identifying the eight potential areas where MSM most frequently visited, the team members distributed a brooch (tag) in the contact area (Day 1). We used the brooch because it was simply and quite normal in Thailand for travelers receiving the brooch from an entertainment place as a gift. MSM who visited the selected areas were asked to receive the brooch and were requested to keep it with them for a week because we planned to begin the recapture survey after a week. As some MSMs moved from one venue to another, before being given a brooch, each MSM was asked whether he had already received one. If someone claimed that he had already received a brooch, he was asked to show it. If he failed to show the brooch, the survey team would verify his statement by asking pertinent questions, such as where, when, and from whom he received the brooch.

For the beginning of the survey, the researcher asked the NGOs who work along with the MSM group and the owners of the place to explore the peak days of their customers. The MSMs come to the contact venues at around $9-12$ pm for pubs and bars, 10 - 
$12 \mathrm{pm}$ for public parks, and $8-12 \mathrm{pm}$ for massage parlors. The survey teams began their work between $7.30-12 \mathrm{pm}$ and distributed brooches without a break until midnight (Table 1). The members of each team were asked not to overlap with each other's assigned areas, and the distribution of brooches (capture survey) was completed in one day.

The recapture survey began one week after the first capture survey. The recapture survey was conducted with the same schedules, resources, cruising areas and teams as the capture survey. Hence, MSMs were again asked whether they had already received a brooch. Again MSMs who visited remote areas were asked to show their tag, if someone failed to show the brooch, the survey team would verify his statement by asking pertinent questions, such as date, where, when, and from whom he received the brooch. The number of MSMs who had received a brooch during the first capture survey was noted in the field record.

\section{Results}

Totally 8 locations in various types of entertainment places that the MSMs most frequently visited were selected for this study, including 2 boy bars, two male massage parlors, two public parks and two pubs. The survey was scheduled into two stages, including two rounds of capture-recapture. At the first stage, a total of $80 \mathrm{MSMs}$ were captured as the first sample by receiving a brooch (the tag) in the eight places (37 were denied). One week later, the second stage was done; total of 348 MSMs were interviewed on their possible reception of the tags. 38 persons in the second sample reported reception of a brooch. The results of each capture are presented in Table 2. In the round of capture-recapture that consisted of the captures and recaptures utilizing the tag of brooch: $\mathrm{R}=80, \mathrm{C}=348, \mathrm{M}=38$, the estimate of the MSM population size was 733 (95\% CI: 480 - 985) or the estimation of MSM population in Chiang Mai Thailand was $7.3 \%(95 \% \mathrm{CI}=7.1-14.1)$.

\section{Discussion}

The capture-recapture method was originally used in wildlife research over 100 years

Table 1. Physical mapping of the location.

\begin{tabular}{cccc}
\hline Location & Type & Peak/Days & Visited \\
\hline Location 1 & Bar A & Weekend/9-12 pm & $7.30-12 \mathrm{pm}$ \\
Location 2 & Bar B & Weekend/9-12 pm & $7.30-12 \mathrm{pm}$ \\
Location 3 & Massage parlor A & $8-12 \mathrm{pm}$ & $7.30-12 \mathrm{pm}$ \\
Location 4 & Massage parlor B & Weekend/8 - 12 pm & $7.30-12 \mathrm{pm}$ \\
Location 5 & Public park A & $10-12 \mathrm{pm}$ & $7.30-12 \mathrm{pm}$ \\
Location 6 & Public park B & $10-12 \mathrm{pm}$ & $7.30-12 \mathrm{pm}$ \\
Location 7 & Pub A & Fri- Sat $/ 9-12 \mathrm{pm}$ & $7.30-12 \mathrm{pm}$ \\
Location 8 & Pub B & Weekend/9-12 pm & $7.30-12 \mathrm{pm}$ \\
\hline
\end{tabular}


Table 2. Result of the second capture and second recapture.

\begin{tabular}{|c|c|c|c|c|c|c|c|}
\hline Location & Second capture & $\begin{array}{c}\text { Second } \\
\text { recapture }\end{array}$ & $\begin{array}{c}\text { Estimated } \\
\text { population }\end{array}$ & Cumulative Second capture & $\begin{array}{c}\text { Cumulative Second } \\
\text { recapture }\end{array}$ & $\begin{array}{c}\text { Estimated } \\
\text { population }\end{array}$ & $95 \% \mathrm{CI}$ \\
\hline Bar A & 65 & 5 & 1040 & 65 & 5 & 1040 & $847-1232$ \\
\hline Massage parlor A & 32 & 3 & 853 & 149 & 10 & 1192 & $805-901$ \\
\hline Massage parlor B & 28 & 3 & 747 & 177 & 13 & 1089 & $710-783$ \\
\hline Public park B & 21 & 4 & 420 & 213 & 22 & 775 & $360-479$ \\
\hline Pub A & 72 & 9 & 640 & 285 & 31 & 736 & $366-913$ \\
\hline Pub B & 63 & 7 & 720 & 348 & 38 & 733 & $480-959$ \\
\hline Total & 348 & 38 & 733 & & & & $480-985$ \\
\hline
\end{tabular}

ago [14]. It estimated the size of rare and elusive populations, which are difficult to find and count or which are very mobile and cannot be counted at one time. During the last decade, the method has been applied to estimate the sizes of those hidden or difficult-to-reach human populations such as sex workers (SWs), homeless persons, and intravenous drug users. This study used a two-stage CR calculation to estimate that there were 733 MSM or $7.3 \%$ in Chiang Mai Thailand. In total, 348 MSM were contacted through trained peer enumerators and the brooch (tag) extended. Of these, 80 were contacted in a single day, offering avenues for this study.

Despite high community stigma and legal concerns, the group of MSM is a hard to reach population and previous study also confirmed the high prevalence of HIV and STDs among this groups [4] [5] [7]. Previous studies documented that four assumptions underlie the CR methodology [12] [16]: the population must be closed, the capture history of each member accurate, capture sources independent, and the probability of being captured during both rounds equal. In this study, the MSM population was not completely closed, but little change would have been expected over the period of 1 week; we also used training and supervision of enumerators or research assistants which helped to ensure capture accuracy. For organizational and safety reasons, enumerators visited the same locations on both rounds. Specific methodologies varied from research to research. In some cases, the varied CR methods that are closer to that were originally used with animal populations, for example, directly capturing, tagging, and recapturing the subjects. In other studies, estimation of population sizes was done by CR indirectly applied to lists that were obtained from clinics, treatment centers, or other services [16]. Male homosexuality is secret in Thailand, and few lists could be referred to for CR method. Therefore, this study chose the original application of the method. In addition, we conducted CR by selecting the various locations to produce accurate results, which could verify each other. These results show differences and suggest possible significant variations in the recapture rates in different places, also confirmed by the study of Luan R. in China [16], and they indicated more locations should be involved in the studies where CR method is used. 
The MSM's visits to the selected places remained relatively unstable, which, however, decreased after a long holiday. We collected data two weeks after for the New Year celebration, when the subjects' visits became much fewer. The change resulted in significant effect upon the precision of this short-term study. It is suggested that future study should be scheduled for the time of year not affected by the long holiday. The other specific techniques such as multiplier method [17] need to be conducted to compare with CR. Because of the limited time and budget, we had only a total of one week and two rounds for the survey. We thus recommend future study to add one more week and a third round of recapture.

\section{Conclusion}

In conclusion, reaching out and contacting MSM groups and their communities were done with a view to reducing HIV and STDs transmission. The CR technique is appropriate for estimating the size of the MSM groups for HIV public health intervention, when targeting HIV prevention strategies towards MSM is urgently needed.

\section{Acknowledgements}

We would like to thank the research assistants for their dedication and support, all participants who supported the benefit data, and Chiang Mai Health Provincial Office for information about MSM. This study was fully supported by Naresuan University Thailand and Shanghai Municipal Center for Disease Control \& Prevention (SCDC), P.R. China. We also appreciated to Centre of Excellence in Molecular Biotechnology (CEMB), Naresuan University for manuscript preparation.

\section{References}

[1] USAID (2011) Men Who Have Sex with Men and Transgender Populations Multi-City Initiative. The UNDP Asia-Pacific Regional Centre, Bangkok.

[2] Mimiaga, M.J., Goldhammer, H., Belanoff, C., Tetu, A.M. and Mayer, K.H. (2007) Men Who Have Sex With Men: Perceptions About Sexual Risk, HIV and Sexually Transmitted Disease Testing, and Provider Communication. Sexually Transmitted Diseases, 34, 113-119. https://doi.org/10.1097/01.olq.0000225327.13214.bf

[3] Fisher, N., Turner, S.W., Pugh, R. and Taylor, C. (1994) Estimating Numbers of Homeless and Homeless Mentally Ill People in North East Westminster by Using Capture-Recapture Analysis. British Medical Journal, 308, 27-30. https://doi.org/10.1136/bmj.308.6920.27

[4] UNAIDS (2010) Estimating the Size of Populations Most at Risk to HIV Infection. UNAIDS, Geneva.

[5] van Griensven, F., de Lind van Wijngaarden, J.W., Baral, S. and Grulich, A. (2009) The Global Epidemic of HIV Infection among Men Who Have Sex with Men. Current Opinion in HIV and AIDS, 4, 300-307. https://doi.org/10.1097/COH.0b013e32832c3bb3

[6] Beyrer, C., Sripaipan, T., Tovanabutra, S., Jittiwutikarn, J., Suriyanon, V., et al. (2005) High HIV, Hepatitis C and Sexual Risks among Drug-Using Men Who Have Sex with Men in Northern Thailand. AIDS, 19, 1535-1540. https://doi.org/10.1097/01.aids.0000183122.01583.c7

[7] van Griensven, F., Varangrat, A., Wimonsate, W., Tanpradech, S., Kladsawad, K., Chemna- 
siri, T., Suksripanich, O., Phanuphak, P., MappStats, P., Kanggarnrua, K., McNicholl, J. and Plipat, T. (2010) Trends in HIV Prevalence, Estimated HIV Incidence, and Risk Behavior Among Men Who Have Sex with Men in Bangkok, Thailand, 2003-2007. Journal of Acquired Immune Deficiency Syndromes, 53, 234-239.

https://doi.org/10.1097/QAI.0b013e3181c2fc86

[8] WHO (2010) HIV/AIDS among Men Who Have Sex with Men and Transgender Populations in South-East Asia: The Current Situation and National Responses. WHO, New Delhi.

[9] Newman, P.A., Lee, S.-J., Roungprakhon, S. and Tepjan, S. (2012) Demographic and Behavioral Correlates of HIV Risk among Men and Transgender Women Recruited from Gay Entertainment Venues and Community-Based Organizations in Thailand: Implications for HIV Prevention. Prevention Science, 13, 483-492. https://doi.org/10.1007/s11121-012-0275-4

[10] Thaikruea, L. and Seetamanotch, S. (2005) Characteristics and Number of Men Who Have Sex with Men in Phuket, Thailand. Chiangmai Medical Bulletin, 44, 1-7.

[11] Nelson, K.E., Celentano, D.D., Suprasert, S., et al (1993) Risk Factors for HIV Infection among Young Adult Men in Northern Thailand. Journal of the American Medical Association, 270, 955-960. https://doi.org/10.1001/jama.1993.03510080059032

[12] Kruse N., et al. (2003) Participatory Mapping of Sex Trade and Enumeration of Sex Workers Using Capture-Recapture Methodology in Diego-Suarez, Madagascar. Sexually Transmitted Diseases, 30, 664-670. https://doi.org/10.1097/01.OLQ.0000079523.04451.82

[13] Aaron, D.J., Chang, Y.-F., Markovic, N. and LaPorte, R.E. (2003) Estimating the Lesbian Population: A Capture-Recapture Approach. Journal of Epidemiology \& Community Health, 57, 207-209. https://doi.org/10.1136/jech.57.3.207

[14] Tilling, K. (2001) Capture-Recapture Methods-Useful Or Misleading International. Journal of Epidemiology \& Community Health, 30, 12-14.

[15] Geibel, S., et al. (2007) Are You on the Market? A Capture-Recapture Enumeration of Men Who Sell Sex to Men in and around Mombasa, Kenya. AIDS and Behavior, 21, 1349-1354. https://doi.org/10.1097/QAD.0b013e328017f843

[16] Luan, R., et al. (2005) A Study on Methods of Estimating the Population Size of Men Who Have Sex with Men in Southwest China. European Journal of Epidemiology, 20, 581-585.

[17] Luan, R., Zeng, G., Zhang, D., Luo, L., Yuan, P., Liang, B. and Li, Y. (2005) A Study on Methods of Estimating the Population Size of Men Who Have Sex with Men in Southwest China. European Journal of Epidemiology, 20, 581-585.

https://doi.org/10.1007/s10654-005-4305-4 
Submit or recommend next manuscript to SCIRP and we will provide best service for you:

Accepting pre-submission inquiries through Email, Facebook, LinkedIn, Twitter, etc. A wide selection of journals (inclusive of 9 subjects, more than 200 journals)

Providing 24-hour high-quality service

User-friendly online submission system

Fair and swift peer-review system

Efficient typesetting and proofreading procedure

Display of the result of downloads and visits, as well as the number of cited articles

Maximum dissemination of your research work

Submit your manuscript at: http://papersubmission.scirp.org/

Or contactwja@scirp.org 